\title{
CERN head pushes claim for 'safe' reactor
}

Paris. Carlo Rubbia, the director of the European Laboratory for Particle Physics (CERN), has become locked in a dispute with researchers at the Los Alamos National Laboratory in the United States over competing claims for the novelty of techniques which each say is able to produce safe and clean nuclear energy.

Speaking at press conferences in Geneva and Paris last week, Rubbia proposed using proton accelerators to supply neutrons in a new generation of commercial nuclear reactors. These, he said, would eliminate the risk of critical accidents, produce no long-lived highly radioactive waste, and avoid the proliferation of weapons-grade materials such as plutonium.

Rubbia's proposed reactor would use thorium-232, which is plentiful but not readily fissile. Bombarding thorium-232 with neutrons transforms it to fissile uranium233. The fission of this produces more neutrons which breed further uranium-233 and thorium-232; but it does not produce enough neutrons to sustain the reaction.

His proposal, which is based on sophisticated computer simulations, relies on making the reaction self-sustaining by supplying extra neutrons produced by simultaneously bombarding thorium- 232 with protons from an accelerator.

But in a letter last week to the Tribune de Genève, Charles Bowman from Los Alamos claimed that his group had previously described Rubbia's concept in detail, in particular in a paper published last year.

In reply, a spokesperson for Rubbia says that he had not published his work because he had decided to file a patent application when he heard that Bowman had alreadydone so. But the proof that the two discoveries are different lies in the fact that "the two patents are different", says the spokesperson.

Rubbia, who won the Nobel Prize for Physics in 1984 with Simon van der Meer for their discovery of the $\mathrm{W}$ and $\mathrm{Z}$ particles, maintains that his work is oriented towards energy production, whereas that of Bowman's group is aimed at incinerating nuclear waste. He says that his design therefore uses lower neutron fluxes, and could be developed quickly using existing technology.

Bowman argues, however, that his group also explored low neutron fluxes for energy

IMAGE
UNAVAILABLE
FOR
COPYRIGHT
REASONS

production. He says

is it abandoned this

approach because the reactors could 产 not have competed with other designs of nuclear reactors. "Rubbia is reinventing the bicycle, which was already invented here Carlo Rubbia: seeks at Los Alamos," 'something different'. says Bowman. "But it seems he forgot the tyres," namely the elimination of waste.

Industrialists and nuclear experts have already expressed scepticism about claims by Rubbia and others for accelerator-reactors using thorium in general. Rubbia says, for example, that his reactor is inherently safe because it would always be sub-critical.

But Richard Garwin, IBM Fellow Emeritus at the Thomas J. Watson Research Center in New York, says that criticality is not a major issue, and that the only accident to date - at Chernobyl - was exceptional. The real safety problem facing the industry,

\section{EC pays up for Human Frontiers Program}

Strasbourg. The European Commission (EC) has agreed substantially to increase its contribution to the International Human Frontier Science Program (HFSP), which supports research on brain function and molecular approaches to biology.

The EC's decision follows long negotiations with other participants to persuade it to pay its fair share. Japan, which was the original driving force behind the HFSP, at present pays around 80 per cent of the entire budget. North America and Europe each provide half of the remaining sum.

In principle, the contribution of member states is determined by their gross national product (GNP). Until now, the commission, which represents member states of the European Union (EU) who are not among the seven Economic Summit countries, has paid much less than it should have done. But last week it agreed to increase its contribution to the 1993-94 budget from US\$200,000 to US $\$ 896,000$.

The combined GNP of the eight EU member countries which the commission represents is approximately equal to that of France or Germany. The new agreement brings its contribution into line with that offered by those countries.

Michel Cuénod, secretary-general of the HFSP, has welcomed the increase. But he says that the programme's budget of around US\$37 million this year is still far too low. Although about one-third of the grants applications it receives are given positive reviews, only 12 per cent of grant applications can be funded at present.

Cuénod, who spends most of his time fund-raising, says Japan is prepared to pay much more towards the programme if other countries jointly match its current contribution of US $\$ 30$ million. Alison Abbott says Garwin, is the prospect of a meltdown following the failure of a reactor's cooling system; the design of Rubbia's proposed reactor does not affect this.

No-one disputes that Rubbia's reactor would produce similar quantities of shortlived (up to 400 years) waste as conventional pressurized water reactors. But, says Garwin, Rubbia's claim that the reactor would produce negligible quantities of longlived plutonium - 10 grams per tonne of fuel - does not take into account the uranium-238 that Rubbia proposes adding at the beginning of the process.

This spiking is intended to ensure that the uranium-233 could not be used to make weapon's grade material. But Garwin says that the reactor would produce several kilograms of plutonium.

Bowman also claims that Rubbia has failed to state clearly that his reactor would also produce long-lived fission products such as technetium-99 and iodine-129. These are among the most troublesome forms of waste because they dissolve in water and can leak away from geological storage sites.

Nor are industrialists yet banging on Rubbia's door. Jean-Pierre Schwartz, the head of private office of Robert Dautray, chief of the French Atomic Energy Commission (CEA), says that the idea is "worth considering". But he adds that CEA, which is studying accelerators for incinerating waste, has "no immediate plans to explore using accelerators for energy production".

Industry is also cautious. Although particle accelerator-reactors open up new areas for exploration, they will ultimately have to compete with new designs of conventional reactors, and the outcome of this competition will depend on many factors, such as the costs of storing, reprocessing and incinerating wastes.

If uranium prices rise enough, for example, fast-breeder reactors - which are currently out of fashion - may have an advantage over conventional pressurized water reactors. On safety grounds, new designs will also have to compete with the next generation of "very safe" water-cooled reactors which will also be less powerful, so that passive cooling would avoid a meltdown if the cooling system failed.

Undaunted by such arguments, Rubbia says that he intends to pursue the project full-time after he hands over the directorship of CERN to Christopher LlewellynSmith on 31 December. "I've been involved in particle physics all my life," he says. "Now I want to do something different."

Bowman says that he welcomes Rubbia's entry into the field. "He is the only person in Europe standing up to say this work is important," he says. And Bowman adds: "I would be happy to collaborate with him."

Declan Butler 